\title{
Max Winter
}

\section{Hegels formale Geschichtsphilosophie}

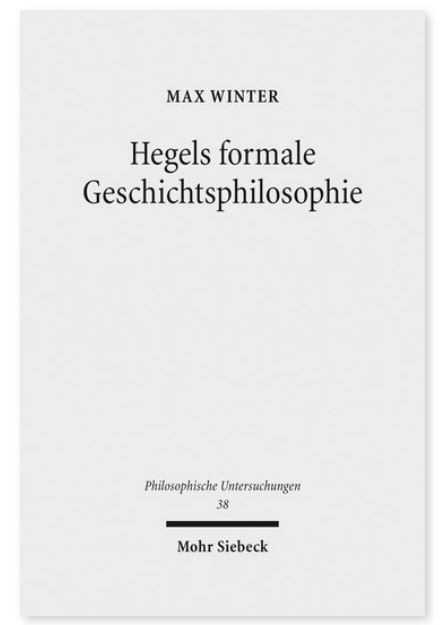

2015. XVII, 209 Seiten. PhU 38

ISBN 978-3-16-153551-2

DOI 10.1628/978-3-16-153551-2

eBook PDF $89,00 €$

ISBN 978-3-16-153511-6

Leinen $89,00 €$
Die gegenwärtige Geschichtsphilosophie in ist in zwei relativ unvermittelte Ansätze geschieden: Der methodologischwissenschaftstheoretischen Analyse geschichtswissenschaftlicher Praxis steht die Reflexion auf die Geschichtlichkeit menschlicher Identität gegenüber. Bisherigen Versuchen zur Überwindung dieser Diskrepanz scheint der Rückgriff auf Hegels Geschichtsdenken versperrt, da dieses weiterhin als Beispiel einer substantialistischen, materialen Geschichtsphilosophie und mithin als theoretisch überholt gilt. Max Winter zeigt, dass Hegel nicht nur über eine theoretisch anspruchsvolle, formale Geschichtsphilosophie verfügt, sondern dass diese darüber hinaus auch geeignet ist, Gräben innerhalb der gegenwärtigen Geschichtsphilosophie zu überbrücken, indem sie eine Epistemologie historischen Wissens mit einer Theorie geschichtlicher Identität verbindet.

Max Winter Geboren 1980; Studium der Philosophie und Geschichtswissenschaft; 2012 Promotion an der Universität Basel; seit 2011 Wissenschaftlicher Mitarbeiter am Lehrstuhl für Praktische Philosophie an der Friedrich-Schiller-Universität Jena.

\section{Jetzt bestellen:}

https://mohrsiebeck.com/buch/hegels-formale-geschichtsphilosophie-9783161535512?no_cache=1 order@mohrsiebeck.com

Telefon: $+49(0) 7071-923-17$

Telefax: $+49(0) 7071-51104$ 